\title{
Contribuições da Educação Permanente para Qualificação da Assistência de Enfermagem em um Hospital Público
}

\author{
Contributions of Permanent Education for Qualification of \\ Nursing Assistance in a Public Hospital
}

\author{
ANA CAROLINA MICHELETTI GOMIDE NOGUEIRA DE SÁ ${ }^{1}$ \\ EDSON RICARDO DE OLIVEIRA FERREIRA ${ }^{2}$ \\ JOYCE DE CARVALHO XAVIER ${ }^{2}$ \\ CARINA MARIAALVES ${ }^{2}$
}

\section{RESUMO}

Objetivo: Analisar as concepções dos profissionais de enfermagem em relação à educação permanente e o quanto esse setor contribuiu para a qualificação das suas ações. Metodologia: Pesquisa qualitativa e quantitativa, descritiva e exploratória, realizada com 113 profissionais de enfermagem em um hospital público na região metropolitana de Belo Horizonte. A coleta de dados ocorreu no período de março a julho de 2016, por meio de questionário semiestruturado. Os dados foram tabulados no Microsoft Excel, versão Office Professional Plus 2010 e analisados de acordo com a análise de conteúdo temática. Resultados: $47 \%$ dos participantes responderam que a educação permanente tem como função promover aperfeiçoamento e $27 \%$ melhorar a assistência prestada aos pacientes. $100 \%$ a apontaram como parte fundamental do trabalho. A motivação para participar das atividades de educação permanente, para $98 \%$ dos participantes foi a necessidade de aprendizagem e aprimoramento e quanto aos fatores que dificultaram a participação, $56 \%$ se referiram a sobrecarga de trabalho. Conclusão: A partir das respostas dos participantes, foi possível perceber que a educação permanente trouxe contribuições quanto aos processos de atualização e capacitação dos profissionais, auxiliando nas atividades que favorecessem o aprendizado, troca de experiências, saberes e reflexão dos processos de trabalho. Constatou-se ainda que a equipe de enfermagem reconhece a importância da educação permanente para a qualificação das suas ações. Em conformidade com a literatura, também foi evidenciado nesse estudo que a sobrecarga de trabalho, cargas horárias exaustivas e falta de recursos materiais dificultaram a participação dos profissionais nas atividades de educação permanente.

\section{DESCRITORES}

Educação Continuada. Equipe de enfermagem. Educação em saúde.

\begin{abstract}
Objective: To analyze the perspective of nursing professionals on permanent education and its contribution to professional development. Material and Methods: This was a qualitative, quantitative, descriptive, exploratory study with 113 nurses from a public hospital in the metropolitan area of Belo Horizonte. A semi structured questionnaire was applied for data collection from March to July 2016. The data were tabulated into Microsoft Office Excel Professional Plus 2010 and analyzed according to the Thematic Content Analysis. Results: $47 \%$ of participants answered that permanent education aims to promote professional development, while $27 \%$ reported that it improves patient care. Permanent education was seen by $100 \%$ of respondents as a fundamental part of the work. In $98 \%$ of the sample, motivation to participate in permanent education actions was the need of learning and improvement. On the other hand, $56 \%$ answered that work overload was a factor that made it difficult to participate. Conclusion: As for the answers given by the participants, it was possible to perceive that permanent education brought contributions to (i) professional development and training, (ii) assisting in the activities that promote learning, as well as (iii) exchange of experiences, knowledge and perspectives on the working process. The nursing team recognizes the importance of permanent education for the development of their actions. Consistently with the literature, This study shows that work overload and lack of material resources hinder participation of professionals in activities related to permanent education.
\end{abstract}

\section{DESCRIPTORS}

Education, Continuing; Nursing, Team; Health Education.

1 Enfermeira e Docente do Programa de Residência Multiprofissional área de ênfase urgência e trauma do Hospital Municipal José Lucas Filho. Contagem/MG, Brasil.

2 Residente do Programa de Residência Multiprofissional área de ênfase urgência e trauma do Hospital Municipal José Lucas Filho. Contagem/MG Brasil. 
$\mathrm{N}$ âmbito da saúde e doença, a enfermagem exerce papel importante dentro da equipe multiprofissional. O seu objetivo direcionase não apenas para o tratamento e recuperação, mas também para a promoção do bem estar, proporcionando um cuidado seguro e eficaz ${ }^{1,2}$. Por estar próxima ao paciente, a equipe de enfermagem é capaz de detectar e intervir sobre suas necessidades, medos e questionamentos, atuando na integralidade. O relacionamento interpessoal é possível e o paciente pode encontrar neste profissional não só a dimensão técnica, mas também a dimensão cuidadora e humanizada ${ }^{3,4}$.

A enfermagem representa mais de $50 \%$ dos trabalhadores em uma instituição hospitalar ${ }^{2,5} \mathrm{e}$ nesta profissão existem fatores que podem interferir na qualidade do trabalho tais como, forte carga emocional e física, jornadas de trabalho extensas, quadro de funcionários reduzido, falta de autonomia e motivação ${ }^{6,7}$, além da desatualização constante dos processos de trabalho. Assim, justifica-se a existência de uma metodologia estimuladora, eficaz e permanente para qualificação desses profissionais.

A educação permanente é o instrumento pelo qual esse processo pode ser alcançado. É uma estratégia instituída pelo Ministério da Saúde, através da portaria GM/MS n 1996 de 20 de Agosto de 2007, que dispõe sobre as diretrizes para a implementação da Política Nacional de Educação Permanente nas instituições de saúde. Segundo esta portaria, a educação permanente pode ser entendida como aprendizagem no trabalho, onde o aprender e o ensinar se incorporam ao dia a dia das organizações ${ }^{8}$. É a partir da realidade local e da individualidade que é possível estabelecer ações que sejam efetivamente recebidas pelos trabaIhadores ${ }^{9}$. Baseia-se na possibilidade de modificar as práticas profissionais, utilizando formas diferenciadas para ensinar, indo além da valorização das técnicas e das capacitações pontuais ${ }^{10}$, tendo o diálogo como a principal ferramenta da educação ${ }^{11}$. Orienta as iniciativas de desenvolvimento dos profissionais, não retirando a responsabilidade pessoal do processo de atualização constante ${ }^{7,12}$.

A formação permanente deve ocorrer em todos os locais, envolvendo vários saberes, promovendo questionamentos quanto à maneira de agir, ao trabalho em equipe, à qualidade da atenção individual e coletiva. $O$ resultado esperado é a sistematização dos ambientes de trabalho, o aperfeiçoamento técnico e cientifico de todos os envolvidos, a busca de soluções criativas para os problemas encontrados e a humanização do cuidado à saúde ${ }^{13}$. Possibilita ao mesmo tempo o desenvolvimento dos profissionais e das instituições ${ }^{13}$, favorecendo assim às demandas da população, dos trabalhadores e dos serviços de saúde ${ }^{8,14}$.

Visando atender à portaria GM/MS n 1996 de 20 de Agosto de 2007 e também às necessidades de desenvolvimento e aperfeiçoamento dos trabalhadores da enfermagem, foi implantado em Julho de 2014 o setor de educação permanente em um hospital público na região metropolitana de Belo Horizonte.

Algumas instituições de saúde possuem um setor denominado "educação continuada, educação permanente ou educação em serviço"2. $\mathrm{Na}$ instituição em estudo optou-se em denominar o setor por "educação permanente", por ser um conceito amplo, que trata de um processo constante e que promove o desenvolvimento dos profissionais de saúde, empregando a reflexão e análise dos problemas reais do cotidiano com a finalidade de alcançar uma aprendizagem significativa ${ }^{2,6}$.

A relevância deste estudo baseou-se na necessidade do desenvolvimento de atividades de educação permanente para equipe de enfermagem, buscando qualidade da assistência e segurança para o paciente e para o profissional que executa o cuidado. Outro fator que justificou esta pesquisa foi a necessidade de conhecer as percepções e anseios da equipe de enfermagem frente à construção de um novo processo de trabalho, com a implantação do setor de educação permanente na instituição em estudo.

Este estudo teve como objetivo analisar as concepções dos profissionais de enfermagem em relação à educação permanente e o quanto este setor contribuiu para a qualificação do trabalho dessa equipe.

\section{MATERIAL E MÉTODOS}

Trata-se de um estudo descritivo, transversal, de caráter qualitativo e quantitativo. A pesquisa qualitativa trabalha com o universo dos significados, com a subjetividade do sujeito que não pode ser traduzida apenas em números. Quanto ao método quantitativo, o conhecimento resultante é baseado em observação e medição ${ }^{15}$. Significa traduzir em números, opiniões e informações para classificá-las e analisá-las ${ }^{15,16}$.

O campo de estudo foi um hospital de média complexidade, localizado na região 
metropolitana de Belo Horizonte, integrado ao Sistema Único de Saúde. O critério para escolha desta instituição foi que a mesma possui o serviço de educação permanente, que tem como missão, contribuir para a formação e o desenvolvimento dos profissionais. Atualmente, o hospital conta com 905 trabalhadores, sendo 608 profissionais de enfermagem, subdivididos em 116 enfermeiros e 492 técnicos em enfermagem.

Para realização do cálculo amostral, utilizou-se a fórmula de amostra aleatória simples, que foi constituída por 113 profissionais de enfermagem (técnicos de enfermagem e enfermeiros), utilizando o nível de confiança de $95 \%$, probabilidade do evento de $90 \%$ e erro amostral de $5 \%$. Como critérios para inclusão no estudo, foram estabelecidos: ser profissional de enfermagem (técnico de enfermagem ou enfermeiro), concordar em participar da pesquisa assinando o Termo de Consentimento Livre e Esclarecido (TCLE) e responder a um questionário, tendo índice de resposta maior ou igual a $70 \%$. Foram excluídos do estudo os profissionais de enfermagem com preenchimento incompleto do questionário inferior a $70 \%$.

Para coleta dos dados, os pesquisadores construíram um questionário semiestruturado, contendo perguntas abertas e semiabertas. Questionário é um instrumento de coleta de dados, constituído por uma série ordenada de perguntas, que devem ser respondidas por escrito ${ }^{17}$. As perguntas seguem no quadro 1 , organizadas como abertas e semiabertas.

Os profissionais de enfermagem foram abordados pelos pesquisadores em seus setores de atuação e convidados para participar da pesquisa, durante o período de trabalho, nos turnos diurno e noturno. Os questionários foram aplicados pelos autores do estudo após esclarecimentos em relação aos objetivos da pesquisa, aspectos éticos, garantia do anonimato e quanto ao direito de desistência em qualquer etapa do estudo, conforme as recomendações da Resolução 466/12 sobre pesquisas envolvendo Seres Humanos ${ }^{18}$. Cada participante recebeu uma cópia do TCLE. Os participantes foram identificados através de códigos, em que enfermeiros foram codificados pelas letras ENF e técnicos em enfermagem pelas letras TEC, seguidos de um algarismo numérico para diferenciá- los: enfermeiro 1 (ENF 1), técnico em enfermagem 1 (TEC 1) e assim sucessivamente. A coleta dos dados ocorreu no período de Março a Julho de 2016.

Para a tabulação dos dados coletados, utilizou-se o programa Microsoft Excel versão Office Professional Plus 2010, sendo calculada frequência absoluta e a porcentagem de cada resposta do questionário. Os dados relacionados à divisão dos participantes por categoria profissional, setores e turnos de trabalho, foram dispostos na Tabela 1. As respostas abertas e as semiabertas foram submetidas à análise de conteúdo na modalidade temática, seguindo as fases de pré-análise; exploração do material; tratamento dos resultados obtidos, inferências e interpretação ${ }^{19,20}$.

Esta pesquisa foi aprovada pelo Comitê de Ética em Pesquisa do Hospital Felício Rocho, conforme o CAAE 51759415.5.0000.5125 e número de parecer 1.439.917.

\section{RESULTADOS E DISCUSSÕES}

Dos 113 profissionais participantes da pesquisa, foram 27 (24\%) enfermeiros e 86 (76\%) técnicos em enfermagem. Quanto à divisão dos participantes por categoria profissional, setores e turnos de trabalho, segue Tabela 1.

Após a análise do conteúdo, as respostas ao questionário foram categorizadas em: educação permanente segundo a ótica dos profissionais; a equipe de enfermagem e as ações educativas; avaliação dos temas abordados nas ações educativas e levantamento das necessidades para novas ações.

\section{Educação permanente segundo a ótica dos profissionais}

Em relação à função da educação permanente, as respostas mais frequentes foram: dar treinamentos e manter os profissionais atualizados 47 (42\%); promover o aperfeiçoamento $31(27 \%)$; melhorar a assistência prestada aos pacientes 15 $(13 \%)$; trazer novidades $10(9 \%)$. Reciclar, esclarecer dúvidas, permitir reflexão sobre a prática diária, ser um elo entre o conhecimento e o profissional e trazer melhorias para instituição foram respostas citadas com menor frequência 10 (9\%). 


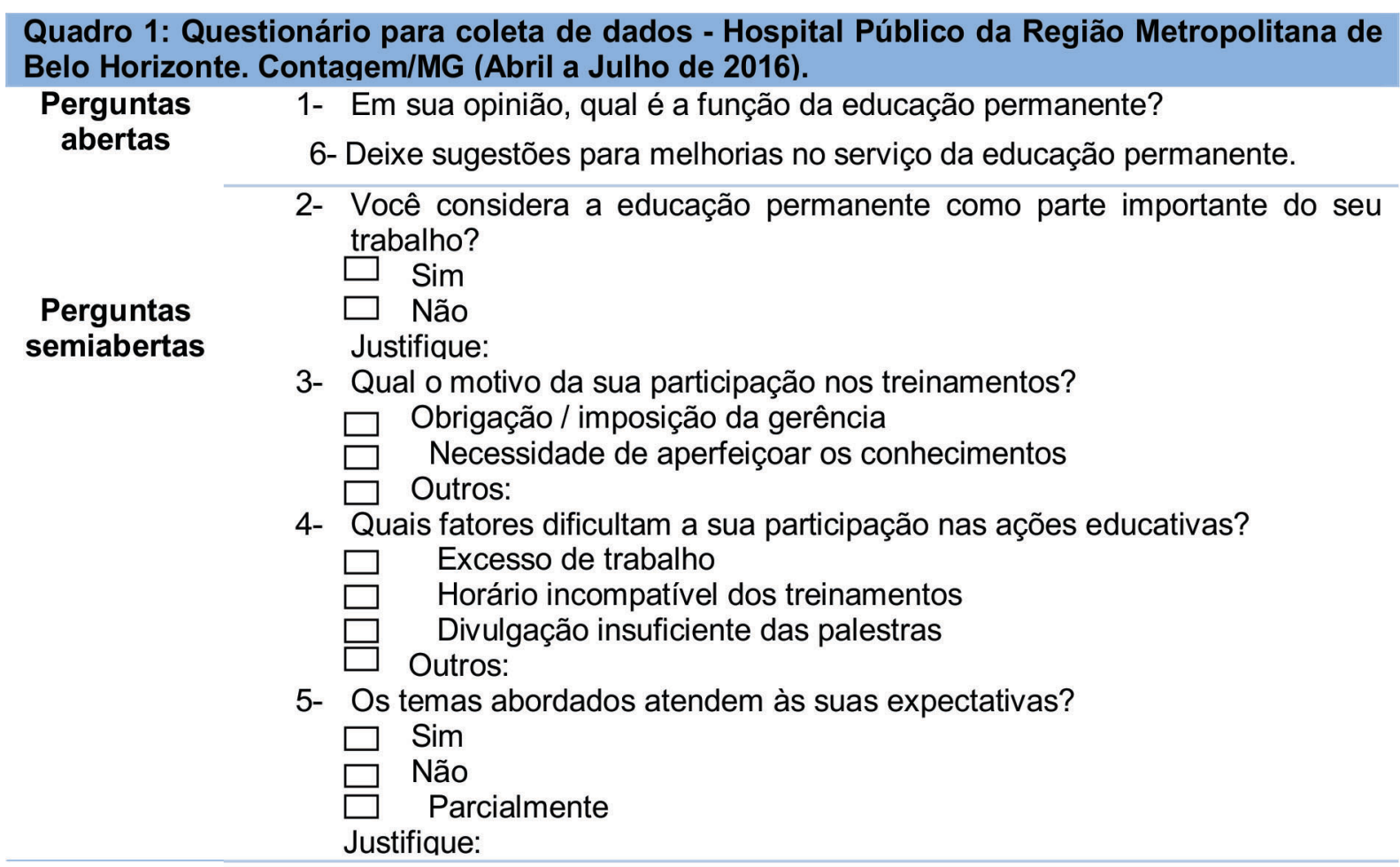

\begin{tabular}{|c|c|c|c|c|}
\hline \multirow[t]{2}{*}{ Setores } & \multicolumn{2}{|c|}{ Enfermeiros } & \multicolumn{2}{|c|}{$\begin{array}{l}\text { Técnicos em } \\
\text { enfermagem }\end{array}$} \\
\hline & Diurno & Noturno & Diurno & Noturno \\
\hline Clínica Médica & $08(7 \%)$ & - & $21(19 \%)$ & $03(3 \%)$ \\
\hline CTI adulto & $05(4 \%)$ & $01(1 \%)$ & 07 (6\%) & 09 (8\%) \\
\hline Pronto Socorro & - & - & 06 (5\%) & - \\
\hline Maternidade & $02(2 \%)$ & $01(1 \%)$ & $07(6 \%)$ & $07(6 \%)$ \\
\hline Pediatria & $04(3 \%)$ & - & $05(4 \%)$ & $01(1 \%)$ \\
\hline Clinica cirúrgica & $01(1 \%)$ & $01(1 \%)$ & $09(8 \%)$ & $01(1 \%)$ \\
\hline Bloco cirúrgico & - & $01(1 \%)$ & 03 (3\%) & - \\
\hline $\begin{array}{l}\text { Outros setores ( } \mathrm{CCIH} \text {, apoio } \\
\text { diaqnóstico, curativos) }\end{array}$ & $03(3 \%)$ & - & $07(6 \%)$ & - \\
\hline Total & $23(20 \%)$ & $04(4 \%)$ & $65(57 \%)$ & $21(19 \%)$ \\
\hline
\end{tabular}

"A função da educação permanente é através de palestras e treinamentos, orientar os funcionários sobre assuntos relacionados à saúde." (TEC 78)

"Realizar reciclagem com os colaboradores e trazer atualizações para garantir uma assistência melhor." (TEC 6)
"Ela nos possibilita a fazermos um trabalho melhor, com a consciência de estarmos fazendo o exigido pelo setor onde trabalhamos." (TEC 20)

De acordo com as respostas, os profissionais consideraram que a educação permanente 
contribuiu para a atualização e para o aprimoramento das suas práticas, melhorando assim a assistência prestada. Contudo, observou-se que a maioria dos entrevistados definiu como função da educação permanente a realização de treinamentos e atualização dos procedimentos assistenciais. As definições atribuídas fazem parte do processo educativo em saúde, entretanto o universo da educação permanente possui conceitos e funções que representam um processo mais amplo ${ }^{2,6}$, se comparadas às respostas obtidas.

A função da educação permanente vai além de oferecer treinamentos ou capacitações. Busca promover reflexões da prática profissional com base no cotidiano, considerando a realidade e as necessidades do profissional e da instituição. Objetiva também mudança nos modelos atuais predominantes de formação ${ }^{2}$, atuando como facilitadora das iniciativas de desenvolvimento dos profissionais e das estratégias de transformação das práticas de saúde ${ }^{21}$.

A educação permanente é algo desafiante, que deve causar impacto no que é subjetivo em cada um, possibilitando uma formação crítica, para que os conhecimentos obtidos influenciem no modo de pensar e atuar ${ }^{22}$. Ensinar não é transferir conhecimento, mas promover e incentivar as possibilidades para a sua própria construção ${ }^{11}$.

Todos os entrevistados, 113 (100\%) consideraram a educação permanente como parte fundamental do seu trabalho.

"Creio que estou capacitada, porém, não excluo a necessidade de aprender a cada dia e melhorar alguns pontos e dificuldades para tornar ainda melhor a prestação do serviço." (TEC 5)

"Traz motivação para a procura de novas práticas e descobertas." (ENF 17)

"É importante, por que motiva a reflexão e mudança de postura diante do trabalho." (ENF 4)

"Por que ela vem orientar, educar e informar, além de promover reflexões acerca de assuntos relacionados à saúde." (ENF 19) "Por que a educação permanente é um elo entre o profissional e o conhecimento." (ENF 10)

A educação permanente pode ser percebida como parceira dos profissionais, estando presente no dia a dia e permitindo a construção e o compartilhamento das experiências ${ }^{8}$. De acordo com as respostas, os participantes confiam à educação permanente as suas expectativas de aprendizagem e a visualizam como oportunidade para aprimorar a assistência prestada. Desta forma observou-se que a implantação do setor de educação permanente no hospital público, contribuiu para a compreensão e incorporação de conceitos, como refletir frente ao trabalho. Também observou-se que o setor alcançou algumas expectativas dos participantes quanto às necessidades de ações que favorecessem o aprendizado para auxiliá-los a lidar com situações do serviço.

A educação permanente proporciona uma releitura crítica das condições de trabalho, das relações estabelecidas e das necessidades de saúde $^{22}$. Na formação permanente, o momento principal é o do pensamento crítico sobre a prática, pois, é refletindo criticamente a prática de ontem que se pode melhorar a prática de amanhã ${ }^{11}$. É considerada uma importante ferramenta para construção da competência do profissional ${ }^{23}$, sendo o elo entre o mundo da formação e do trabalho ${ }^{24}$.

\section{A equipe de enfermagem e as ações educativas}

Em relação ao motivo que levou a participação dos profissionais nas atividades desenvolvidas pelo setor de educação permanente, $108(96 \%)$ responderam que a necessidade de aprendizagem e aperfeiçoamento foram os fatores principais e 5 (4\%) participaram por obrigação ou imposição da gerência setorial.

"Aquisição de novos conhecimentos e tecnologias." (ENF 1)

"Necessidade de aperfeiçoar, por que a tecnologia muda a cada dia." (TEC 7)

"Gosto de aprender coisas novas." (TEC 65)

"Obrigação / imposição da gerência." (TEC 80)

Os dados apontaram que a maioria dos participantes se envolveu nas atividades educativas em busca de crescimento próprio, aquisição de novos saberes. Entretanto, alguns declararam a sua participação por determinação dos gerentes.

Para que um processo educativo seja eficiente, é fundamental que o profissional se apresente espontâneo, disponível e motivado, cooperando com esse processo ${ }^{9}$. É importante ressaltar que os serviços de saúde são campos da atuação de vários profissionais que apresentam intenções diferentes. No entanto, a condição fundamental para que um trabalhador ou instituição resolva sobre mudanças nas suas práticas ou modos de fazer, é o incomodo, ou seja, a percepção de que a forma atual de pensar é insuficiente ou inadequada para dar conta dos desafios do seu trabalho ${ }^{9}$. É preciso instituir estratégias de educação que encorajem a participação do trabalhadores ${ }^{6} .0$ 
sucesso do processo de aprendizagem dependerá da atuação de cada serviço e de cada profissional ${ }^{25}$.

Quanto aos fatores que dificultaram a participação nas ações educativas: sobrecarga de trabalho nos setores 52 (46\%); horários incompatíveis dos treinamentos com as atividades nos setores 37 (33\%); divulgação insuficiente das atividades educativas $9(8 \%)$. Não existem dificuldades ou impedimentos 13 (11\%); não responderam $2(2 \%)$.

\section{"Largar o trabalho acumula tarefas." (TEC 49)}

"As condições inadequadas de trabalho geram atraso, perda de tempo." (TEC 72)

"Mesmo que os treinamentos aconteçam no meu horário de trabalho, às vezes as demandas dos pacientes não me permitem sair do setor." (ENF 4)

"Sempre temos muitas tarefas. Acredito que os treinamentos in loco são bem mais aproveitados." (ENF 6)

"O que se torna mais difícil é tirar os técnicos no horário do plantão para participar dos treinamentos." (ENF 13)

As respostas acima mostraram que as tarefas rotineiras de cuidados aos pacientes nos setores de trabalho foram priorizadas em detrimento da educação em serviço. Para os profissionais, sair dos setores nos horários de trabalho para participar das atividades educativas poderia gerar acúmulo de tarefas e atrasos nas atividades assistenciais. A condição inadequada do trabalho também foi descrita como fator impeditivo ou desfavorável para a participação, conforme a resposta do participante TEC 72.

As cargas horárias exaustivas e a falta de material para a realização de procedimentos podem contribuir para que o tempo destinado ao aperfeiçoamento profissional seja reduzido ${ }^{26}$. A duração dos treinamentos também deve ser observada, pois atividades muito longas podem ser cansativas e improdutivas ${ }^{27}$.

Para que o aprendizado aconteça por meio das atividades educativas em serviço, é preciso existir comprometimento entre as partes: profissional, educação permanente e instituição. Cada profissional precisa se envolver com esse processo educativo priorizando a sua participação, por sua vez, a educação permanente deve ser realizada considerando-se o contexto em que os profissionais estão inseridos, a realidade institucional e as condições de trabalho oferecidas ${ }^{25}$.

\section{Avaliação dos temas abordados e levantamento das necessidades para novas ações educativas}

Em relação à satisfação dos participantes com os temas abordados, 91 (81\%) afirmaram que os assuntos atenderam às suas expectativas e 22 (19\%) atenderam parcialmente.

"Os temas oferecidos e abordados nos
treinamentos estão dentro das nossas
necessidades." (ENF 13)
"Parcialmente. O assunto às vezes é muito
complexo para pouco tempo." (TEC 1)
"Parcialmente, pois não há necessidade de
abordar o mesmo tema inúmeras vezes,
como por exemplo, lavagem das mãos,"
(TEC 82)

Os assuntos abordados pelo setor de educação permanente do hospital em estudo são definidos de acordo com as demandas dos profissionais e da instituição, por meio de pesquisa para sugestões de temas. A partir das questões identificadas, é estabelecido um cronograma anual de atividades, sendo este flexível às novas demandas que possam surgir. Assim, alguns temas podem ser repetidos e temas novos inseridos.

A proposta de ensino utilizada na capacitação permanente precisa considerar os trabalhadores como membros de um processo de construção social e de saberes ${ }^{6}$. Os conteúdos abordados devem estar contextualizados com a realidade da instituição de saúde, considerando as características de cada setor e as necessidades do profissional. Propostas pedagógicas separadas da realidade tendem a ser desmotivadoras e improdutivas ${ }^{2}$.

No campo de sugestões para melhorias das ações da educação permanente, não opinaram 31 $(27 \%)$. Dentre os que responderam, as sugestões mais citadas foram: horários para treinamentos compatíveis com as rotinas do setor com um cronograma que permita abordagem de um mesmo tema em dias alternativos 42 (37\%); realização de ações "in loco", em rodas de conversas $8(7 \%)$; ter ações educativas com maior frequência 5 (4\%).

"Os horários deveriam ser mais flexíveis, mais datas disponíveis para o mesmo plantão." (TEC 12)

"Deveria ter horário protegido para educação permanente. Realização de capacitações in loco, visando discutir as questões reais do atendimento. Rodas de conversas." (ENF 4)

$\mathrm{Na}$ instituição em estudo, as atividades 
educativas aconteceram nos períodos da manhã, tarde e noite, estando disponíveis dois horários em cada período. Ainda assim, os resultados apontaram para desajustes desses horários, sendo necessário repensar alternativas para realização das atividades educativas, buscando favorecer a participação e alcançar outros profissionais.

O participante ENF 4 sugeriu a realização das atividades de educação permanente nos próprios setores de trabalho, o que facilitaria a participação dos trabalhadores. Também sugeriu que fossem realizadas rodas de conversas. As rodas de conversas são formas educativas de abordagem aos trabalhadores, possibilitam a abertura de espaços de encontros informais, permitindo a escuta e troca de saberes através da interação entre trabalhadores e facilitadores, considerando o conhecimento que cada um possui sobre o assunto $^{28}$

Um programa de educação eficiente e eficaz deve possuir a flexibilidade necessária para se adaptar à realidade dos trabalhadores ${ }^{2}$.

Quanto aos temas sugeridos, atendimento à parada cardiorrespiratória (PCR) 13 (11\%); cuidados com ventilação mecânica 5 (4\%); ética profissional 5 (4\%). Outros temas foram citados com menor frequência, como administração de medicamentos e controle de infecção hospitalar.

"Mais palestras sobre respirador, mas o assunto deverá ser fracionado, pois o tema é complexo." (TEC 1)

"Cursos práticos rápidos, exemplo PCR." (ENF 5)

"Ética profissional e comportamento diante dos pacientes." (TEC 13)

Temas mais complexos relacionados à urgência e emergência foram os mais sugeridos, refletindo a preocupação da equipe assistencial com as dificuldades encontradas no dia a dia e evidenciando a necessidade de maior aprimoramento, uma vez que por se tratar de um hospital de média complexidade, essas situações ocorrem com frequência.

A demanda para ação educativa deve ser determinada a partir da solicitação do trabalhador diante dos problemas enfrentados na execução do cuidado $^{2,14}$. Os conteúdos devem considerar o cotidiano do trabalho, da instituição e a evolução tecnológica² ${ }^{2}$ É importante que se abordem assuntos para a formação de competências e atitudes e que os profissionais sejam estimulados a discutirem aspectos relacionados à comunicação, tomada de decisão e trabalho em equipe, assim como o papel do sistema de saúde do qual fazem parte ${ }^{29}$.

\section{Limitações do estudo}

Esta pesquisa apresentou limitações, pois se desenvolveu em um contexto de trabalho específico, com profissionais de saúde inseridos em determinado contexto econômico e social, que vivenciam determinada realidade e organização própria. Essas fragilidades futuramente poderão ser objeto de estudo para novos ajustes e contribuições para meio acadêmico.

\section{CONCLUSÃO}

Os resultados desta pesquisa indicaram que as concepções dos trabalhadores em relação à educação permanente necessitam ser exploradas e trabalhadas. Os participantes desse estudo atribuíram como sendo função da educação permanente, a realização de treinamentos e atualização. Os conceitos e funções da educação permanente são amplos, portanto, se entendidos adequadamente poderão contribuir significativamente para a sensibilização desses profissionais, levando-os a refletir e buscar possibilidades para uma nova formação em saúde.

Verificou-se que a equipe de enfermagem reconhece a importância da educação permanente como parceira para a qualificação das suas ações, compreendendo-a como orientadora e facilitadora das suas práticas assistenciais diárias. Trouxe contribuições para os profissionais em suas expectativas quanto aos processos de atualização e capacitação, auxiliando nas atividades que favorecessem o aprendizado, troca de experiências, conhecimentos e saberes dos processos de trabalho.

Ainda assim, foram apontados alguns entraves que influenciaram o desenvolvimento das atividades educativas e o aprendizado, relacionados às condições de trabalho, dificuldades para estabelecer horários compatíveis entre as atividades educativas e as rotinas de trabalho dos profissionais, preocupação com o tempo destinado para participar de atividades educativas, o acúmulo de tarefas assistenciais e a desmotivação da equipe. Outro aspecto evidenciado, é que o processo de trabalho e a sua forma de organização são fatores determinantes para o sucesso das propostas educativas. A efetividade do aprendizado acontecerá se for estabelecido um elo entre as partes: profissionais, educação permanente e instituição. Estas têm por responsabilidade se manter interligadas, favorecendo que as atividades educativas gerem inquietude nos envolvidos, o que proporcionará reflexão das práticas cotidianas e busca pela melhoria. 


\section{REFERENCIAS}

1. Brito RF, Fonseca RBG, Alves CM, Vieira CL, Faria DM, Azevedo $\mathrm{JH}$, et al. $\mathrm{O}$ cuidado de enfermagem em sua dimensão bioética: um relato de experiência a partir do trabalho integrado no sétimo período do curso de enfermagem da PUC Minas em Betim. Brito RF, Moraes RMS, Organizadores. Educar para saúde: experiências do laboratório de educação para saúde do Curso de Enfermagem da PUC Minas em Betim: Pró-saúde: integração ensino-serviços de saúde. Belo Horizonte: Editora PUC Minas; 2008

2. Silva GM, Seiffert OMLB. Educação continuada em enfermagem: uma proposta metodológica. Rev. bras. enferm. 2009; 62(3): 362-366.

3. Reichert APS, Lins RNP, Collet N. Humanização do cuidado da UTI Neonatal. Rev Eletr Enferm. 2007; 9(1): 200-13.

4. Bonfim ECG, Sampaio J, Pascoal FFS. Integração ensinoserviço: experiência da gestão da educação na saúde. Rev. Enferm. UFPE. 2014; 8(7): 2551-6.

5. Isaacs LG, Montes M, Rodríguez A, Sena RR, Silva L, Tascon EC. As pessoas são importantes: educação permanente do pessoal de enfermagem. In: Arriagada J, Canaval GE, Ceballos NE, Sena RR, Villalobos MMD. Recursos de Enfermagem: contribuições ao processo de desenvolvimento. Bogotá: Unibiblos; 2001. 136-165.

6. Sardinha PL, Cuzatis GL, Dutra CT, Tavares CMM, Dantas CAC, Antunes CE. Educação permanente, continuada e em serviço: desvendando seus conceitos. Enf. glob. 2013; 12(29): 307-322.

7. Girade MG, Cruz EMNT, Stefanelli MC. Educação continuada em enfermagem psiquiátrica: reflexão sobre conceitos. Rev. esc. enferm. USP. 2006; 40(1): 105110.

8. Brasil. Ministério da Saúde. Portaria $n^{\circ}$. 1 996/GM/MS, de 20 de agosto de 2007. Dispõe sobre as diretrizes para a implementação da Política Nacional de Educação Permanente em Saúde e dá outras providências. Brasília: MS; 2007.

9. Merhy EE, Feuerwerker LCM. Educação Permanente em Saúde: educação, saúde, gestão e produção do cuidado. In: Mandarino ACS, Gallo E, Gomberg E, organizadores. Informar e Educar em Saúde: análises e experiências. Salvador: Editora da UFBA; 2011.

10. Silva LAA, Franco GP, Leite MT, Pinno C, Lima VML, Saraiva N. Concepções educativas que permeiam os planos regionais de educação permanente em saúde. Texto contexto - enferm. 2011; 20(2): 340-8.

11. Freire P. Pedagogia da autonomia: Saberes Necessários à Prática Educativa. 25. ed. São Paulo: Paz e Terra; 1996.

12. Ricaldoni CAC, Sena RR. Educação permanente: uma ferramenta para pensar e agir no trabalho de enfermagem. Rev. Latino-Am. Enfermagem. 2006; 14(6): 837-842.

13. Ministério da Saúde (BR). Secretaria de Gestão do Trabalho e da Educação na Saúde. Departamento de Gestão da Educação em Saúde. A educação permanente entra na roda: pólos de educação permanente em saúde: conceitos e caminhos a percorrer. Brasília (DF): MS; 2005.

14. Montanha D, Peduzzi M. Educação permanente em enfermagem: levantamento de necessidades e resultados esperados segundo a concepção dos trabalhadores. Rev. esc. enferm. USP. 2010; 44(3): 597604.
15. Minayo MCS. O desafio do conhecimento. Pesquisa qualitativa em saúde. 9. ed. São Paulo: Hucitec; 2007.

16. Driessnack M, Sousa VD, Mendes IAC. Revisão dos desenhos de pesquisa relevantes para enfermagem: parte 2 - desenhos de pesquisa qualitativa. Revista Latino-Americana de Enferm. 2007; 15 (4): 684-8.

17. Lakatos EMA, Marconi MA. Fundamentos da metodologia científica. 5. ed. São Paulo: Atlas; 2003.

18. Brasil. Ministério da Saúde. Resolução 466 de 12 de Dezembro de 2012. Diretrizes e normas regulamentadoras sobre pesquisa envolvendo seres humanos. Brasília: 2012.

19. Minayo MCS, organizadora. Pesquisa social: teoria método e criatividade. 25. ed. Petrópolis: Vozes; 2001.

20. Campos CJG. Método de análise de conteúdo: ferramenta para a análise de dados qualitativos no campo da saúde. Rev. Bras. Enferm. 2004; 57(5): 611 . 4.

21. Ceccim RB. Educação Permanente em Saúde: desafio ambicioso e necessário. Interface. 2005; 9(16): 161168.

22. Hetti LBE, Bernardes A, Gabriel CS, Fortuna CM, Maziero VG. Educação permanente/continuada como estratégias de gestão no Serviço de Atendimento Móvel de Urgência. Rev. Eletr. Enf. 2013; 15(4): 973-82.

23. Oliveira FMCSN, Ferreira EC, Rufino NA, Santos MSS Educação permanente e qualidade da assistência à saúde: aprendizagem significativa no trabalho da enfermagem. Aquichán. 2011; 11(1): 48-65.

24. Brasil. Ministério da Saúde. Secretaria de Gestão do Trabalho e da Educação em Saúde. Departamento de Gestão da Educação na Saúde. Política de educação e desenvolvimento para o SUS: caminhos para a Educação Permanente em Saúde - Pólos de Educação Permanente em Saúde. Brasília: Ministério da Saúde, 2004.

25. Filho LAM, Marinho CSR, Beackes VNS, Martini JG Educação permanente em saúde: uma estratégia para articular ensino e serviço. Rev Rene. Rio Grande do Norte. 2013; 14(5): 1050-60.

26. Lima SG, Macedo LA, Vidal ML, Sá MPBO. Educação Permanente em SBV e SAVC: impacto no conhecimento dos profissionais de enfermagem. Arq. Bras. Cardiol. 2009; 93 (6): 630-6.

27. Braga AT, Melleiro MM. Percepção da equipe de enfermagem acerca de um serviço de educação continuada de um Hospital Universitário. Rev. Esc. Enferm USP. 2009; 43(2): 1216-20.

28. Melo RHV, Felipe MCP, Cunha ATR, Vilar RLA, Pereira EJS, Carneiro NEA, et al. Roda de conversa: uma articulação solidária entre ensino, serviço e comunidade. Rev. bras. educ. med. 2016; 40(2): 301309.

29. Bezerra ALQ, Queiroz ES, Weber J, Munari DB. O processo de educação continuada na visão de enfermeiros em um hospital universitário. Rev. Eletr. de enferm. 2012; 14(3): 618-625.

\section{CORRESPONDÊNCIA}

Carina Maria Alves Santos

Rua Antônio de Pádua Pinto, 157, Santa Helena 32015-040 - Contagem, MG, Brasil

E-mail: carinaalvess@yahoo.com.br 